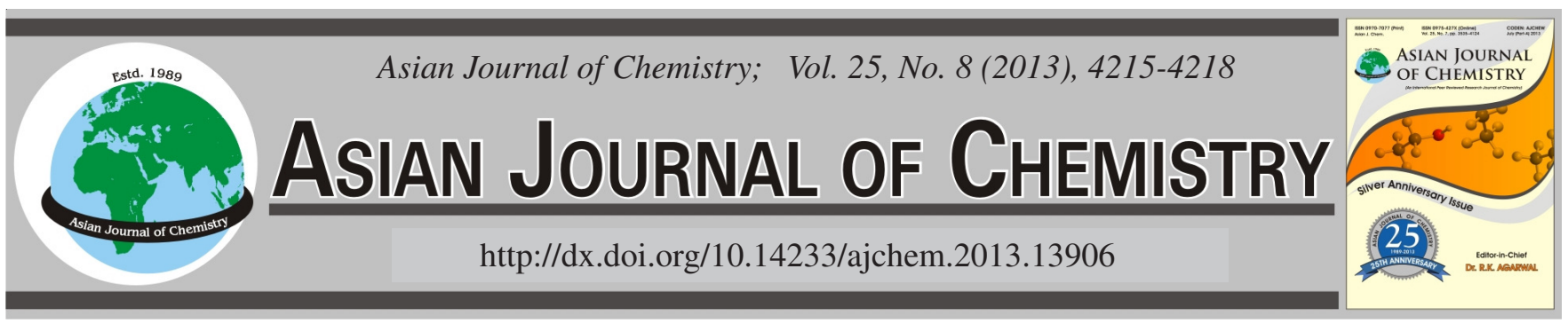

\title{
Spectroscopic Studies and Keto-Enol Tautomeric Effect of Newer Schiff Bases of ortho-Hydroxy- benzaldehyde/naphthaldehyde with 1,2-Phenylenediamine and 4-Aminophenyl Ether
}

\author{
AmbreEn ShaH ${ }^{1, *}$ and Asif A. ShaH ${ }^{2}$
}

${ }^{1}$ Dr. M. A.Kazi Institute of Chemistry, University of Sindh, Jamshoro, Pakistan

${ }^{2}$ Mehran University Institute of Science and Technology Development, Jamshoro, Pakistan

*Corresponding author: Fax: +92 22 2771373; Tel: +92 22 2772325; E-mail: anashba_shah@yahoo.com

(Received: 14 April 2012;

Accepted: 4 February 2013)

AJC-12930

\begin{abstract}
Hydroxyl Schiff bases derived from 1,2-phenylenediamine and 4-aminophenyl ether with $o$-hydroxy benzaldehyde or $o$-hydroxyl naphthaldehyde were used to investigate enol-imine and keto-amine tautomeric analysis. UV-visible spectra of the compounds have been investigated tautomeric equilibrium (enol-imine $\mathrm{O}-\mathrm{H} \cdots \mathrm{N}$, keto- amine $\mathrm{O} \cdots \mathrm{H}-\mathrm{N}$ forms) in different polar and non-polar solvents systems. From FTIR spectra of these model compounds, were possible to assign the IR absorption for the $\mathrm{C}=\mathrm{O}$ and $\mathrm{C}=\mathrm{N}$ groups in both ketoamine and enol imine forms, respectively. The keto-enol forms was observed in basic solution of polar and nonpolar solvents such as ethanol, chloroform, DMF, benzene, cyclohexane, $n$-hexane and in acidic solutions of $\mathrm{CHCl}_{3}$, benzene and $n$-hexane not in ethanol and DMF. FTIR results were showed that all Schiff bases studied, favoured the enol-imine form over the keto form in a weakly polar solvent.

Key Words: Schiff base, Tautomerism, Keto-enamine, Enol-imine, Solvent effect.
\end{abstract}

\section{INTRODUCTION}

Schiff bases with an -OH group on the ortho position to the imine group and their complexes derived from $o$ - hydroxyl benzaldehyde and $o$-hydroxyl naphthaldehyde, were extensively studied and a number of them are being used as model for biological system ${ }^{1-4}$. ortho-Hydroxyl Schiff base ligands are of prime interest mainly due to the presence of $(\mathrm{O}-\mathrm{H} \cdots \mathrm{N}$ and $\mathrm{O} \cdots \mathrm{H}-\mathrm{N}$ ) type hydrogen bonding in tatomerism between enol-imine and keto-enamine forms (Scheme-I).

Popovic et al. ${ }^{5}$ gave the first example of co-existance of the keto-amine or enol-imine forms of diamines with Schiff bases of naphthaldimine compound of $N, N^{\prime}$-bis-(1-naphthaldimine) $o$-phenylenediamine chloroform $(1 / 1)$ at $200 \mathrm{~K}$. In these compounds, the short $\mathrm{H}$ - bonds between the $-\mathrm{OH}$ group on the ortho position to the imino group and imine nitrogen were played important role due to the stereochemistry of imine compounds. Different spectroscopic techniques were used to find the tatoumeric effect in $o$-hydroxy Schiff bases, both in solid state and in solutions $s^{6-11}$. UV-VIS spectroscopy of $o$ hydroxy Schiff bases were studied in both solid state and in solutions $^{12,13}$.

Herzfeld et $a l .{ }^{14,15}$ examined initially the role of acidity and basicity of the solvent in spectra of some Schiff bases and also observed their solvent effect in different solvents. In UVvisible spectra of $o$-hydroxy Schiff bases, a new band is observed at greater than $400 \mathrm{~nm}$, in polar and non-polar solvents. This result indicated that the absorption band at 400 $\mathrm{nm}$ belongs to the keto-amine from of the Schiff base. This tatoumer is always observed when Schiff base is derived from 2-hydroxynaphthaldehyde and aromatic amines. In the $o$ hydroxybenzaldehyde and aromatic amines, the keto amine is not observed in polar and non-polar solvents, but it is observed in acidic media ${ }^{16,17}$. 2-Hydroxy naphthaldehyde was shown two bands in the visible region located above $400 \mathrm{~nm}$, which are assigned to the keto form. In the solid state, 2-hydroxy benzaldehyde, both forms are possible and $\mathrm{O}-\mathrm{H} \cdot \cdots \mathrm{N}$ and $\mathrm{O} \cdots \mathrm{H}-\mathrm{N}$ intramolecular hydrogen bonding can occur ${ }^{18,19}$. Antonov et al. ${ }^{20}$<smiles>[Y]N(/C=C1\C=CC=CC1=O)[Y]([H])/C=C1\C=CC=CC1=O</smiles>

Scheme-I: Tautomerism in newer ortho-hdroxy Schiff bases 
studied the tautomerism of 2-hydroxy naphthaldehyde Schiff bases but Fernande $z^{21}$ reported the structure and solvent effect of ortho-hydroxyl Schiff bases ligands. The effect of substitutions on the keto-enol equlirium mostly observed in crystalline state and extra stabilization of keto form is derived from molecular association, thus leading to its crystallization ${ }^{22}$.

Recently, Zawadiak et al. ${ }^{23}$ investigated that the position of substituted hydroxyl group of compound was shown clear influence on UV absorption spectrum and keto enol equilibrium exist constantly ${ }^{24}$. This present work reports spectroscopic studies of Schiff base formed by the reaction of 2-hydroxybenzaldehyde or 2-hydroxyl naphthaldehyde by the reaction with different diamines; 1,2-phenylenediamine and 4-amino phenyl ether, respectively.

\section{EXPERIMENTAL}

Melting points were recorded on a Gellenkamp capillary melting apparatus (Gallenkemp, England), without correction. Infrared spectra were recorded on a Nicolet Avatar 330 FT- IR (Thermo Nicolet Electron Corporation, USA) with attanulated total reflectance (ATR) accessory (Smart partner) within 4000$600 \mathrm{~cm}^{-1}$. Spectrophotometeric studies were carried out in dimethyl formamide (DMF) and $n$-hexane on double beam Hitachi 220 spectrophotometer [Hitachi (Pvt.) Tokyo, Japan], with dual $1 \mathrm{~cm}$ silica cuvettees within $185-700 \mathrm{~nm}$. All reagents and chemicals were analytical grade, obtained from Aldrich Chemical Company (USA).

Preparation of Schiff base: The Schiff bases was synthesized by reported method, which was the following ${ }^{25}$ : The Schiff base was synthesized by reacting $(0.01 \mathrm{M})$ of diamine compounds (1,2-phenylenediamine or 4-aminophenyl ether dissolved in $10 \mathrm{~mL}$ of $\mathrm{MeOH}$ with $(0.02 \mathrm{M})$ of $o$-hydroxybenzaldehyde/hydroxynaphthaldehyde in the presence of 0.5 gm of anhydrous sodium acetate. After one hour of reflux at $70{ }^{\circ} \mathrm{C}$. The contents were cooled. The obtained precipitate were filtered and recrystallized in ethanol. The Schiff bases were isolated as a light yellow crystalline solid.

Bis-( $O$-hydroxylbenzaldehyde) 1,2-phenylenediimine: Yield: $84.6 \%$; m.p.: $182.9{ }^{\circ} \mathrm{C}$. Analysis of $\left(\mathrm{C}_{28} \mathrm{H}_{20} \mathrm{~N}_{2} \mathrm{O}_{2}\right)$ : Calcd.: C; $80.7 \%$, H; $4.8 \%$, N; $6.7 \%$. Found: C; $79.9 \%$, H; $4.69 \%, \mathrm{~N} ; 6.3 \%$. IR v $\left(\mathrm{cm}^{-1}\right) ; 1610(\mathrm{C}=\mathrm{N}), 1488(\mathrm{C}=\mathrm{C}), 1277$ (C-O) and $1183(\mathrm{C}-\mathrm{N})$.

Bis-(o-hydroxylbenzaldehyde)4-aminophenylether: Yield: $90 \%$; m.p.: $290.4^{\circ} \mathrm{C}$. Analysis of $\left(\mathrm{C}_{20} \mathrm{H}_{16} \mathrm{~N}_{2} \mathrm{O}_{2}\right)$ : Calcd.: C; $75.9 \%, \mathrm{H} ; 5.06 \%, \mathrm{~N} ; 8.8 \%$. Found: C; $73.8 \%$, H; $4.89 \%$, $\mathrm{N} ; 8.13 \%$. IR v $\left(\mathrm{cm}^{-1}\right) ; 1608(\mathrm{C}=\mathrm{N}), 1486(\mathrm{C}=\mathrm{C}), 1276(\mathrm{C}-\mathrm{O})$ and $1182(\mathrm{C}-\mathrm{N})$.

Bis-(o-hydroxylnaphthaldehyde)1,2-phenylenediimine: Yield: $73.9 \%$; m.p.: $176.6{ }^{\circ} \mathrm{C}$. Analysis of $\left(\mathrm{C}_{34} \mathrm{H}_{24} \mathrm{~N}_{2} \mathrm{O}_{3}\right)$ : Calculate: C; $80.3 \%, \mathrm{H} ; 4.72 \%, \mathrm{~N} ; 5.51 \%$. Found: C; 79.8 $\%, \mathrm{H} ; 4.89 \%, \mathrm{~N} ; 5.13 \%$. IR v $\left(\mathrm{cm}^{-1}\right) ; 1610(\mathrm{C}=\mathrm{N}), 1488(\mathrm{C}=\mathrm{C})$, $1275(\mathrm{C}-\mathrm{O})$ and $1186(\mathrm{C}-\mathrm{N})$.

Bis-(o-hydroxylnaphthaldehyd)4-aminophenylether: Yield: $89.7 \%$; mp: $177.2{ }^{\circ} \mathrm{C}$. Analysis of $\left(\mathrm{C}_{26} \mathrm{H}_{20} \mathrm{~N}_{2} \mathrm{O}_{3}\right)$ : Calculate: $\mathrm{C} ; 76.4 \%, \mathrm{H} ; 4.9 \%, \mathrm{~N} ; 6.8 \%$. Found: C; $75.8 \%, \mathrm{H}$; $4.89 \%, \mathrm{~N} ; 6.13 \%$. IR v $\left(\mathrm{cm}^{-1}\right) ; 1611(\mathrm{C}=\mathrm{N}), 1491(\mathrm{C}=\mathrm{C})$, 1241 (C-O) and $1156(\mathrm{C}-\mathrm{N})$.

\section{RESULTS AND DISCUSSION}

Newly synthesized Schiff bases from 1,2-phenylenediimine and 4-aminophenyl ether were shown in (Fig. 1). FTIR spectra of all compounds showed weak and broad absorption bands in the $3400-3200 \mathrm{~cm}^{-1}$ region. This is interpreted to be a sign of the presence of the enol forms schiff bases. Other vibration bands with the wave numbers of 1625-1610 $\mathrm{cm}^{-1} \mathrm{v}(\mathrm{C}=\mathrm{N}), 3080-3040 \mathrm{~cm}^{-1} \mathrm{v}(\mathrm{CH}, \mathrm{Ar}-\mathrm{H}), 1600-1580 \mathrm{~cm}^{-1}$ $v(C=C)$ and $1293-1046 \mathrm{~cm}^{-1} v(C-O-C)$ were observed. From the FTIR spectra of compounds, it was possible to assign the IR absoption for $\mathrm{C}=\mathrm{O}$ and $\mathrm{C}=\mathrm{N}$ group in both keto and enol form, it was also possible to assign other absorption which were specific either to the keto or enol forms ${ }^{8}$. Such as the compound o-hydroxy naphthaldehyde crystallized as a mixture of enol and keto forms with both amines. The enol form was infrared from the presence of strong absorption in the region of 3400-3200 $\mathrm{cm}^{-1}$, while the keto form shown by the strong absorption in the $1700-1660 \mathrm{~cm}^{-1}$ region ${ }^{11}$.

The existence of intramolecular hydrogen bonding $(\mathrm{O} \cdots \mathrm{H}-$ $\mathrm{N}$ ) in solution, has been confirmed by ${ }^{1} \mathrm{H}$ NMR spectroscopy. Mostly all compounds shown the enol-imine form dominates
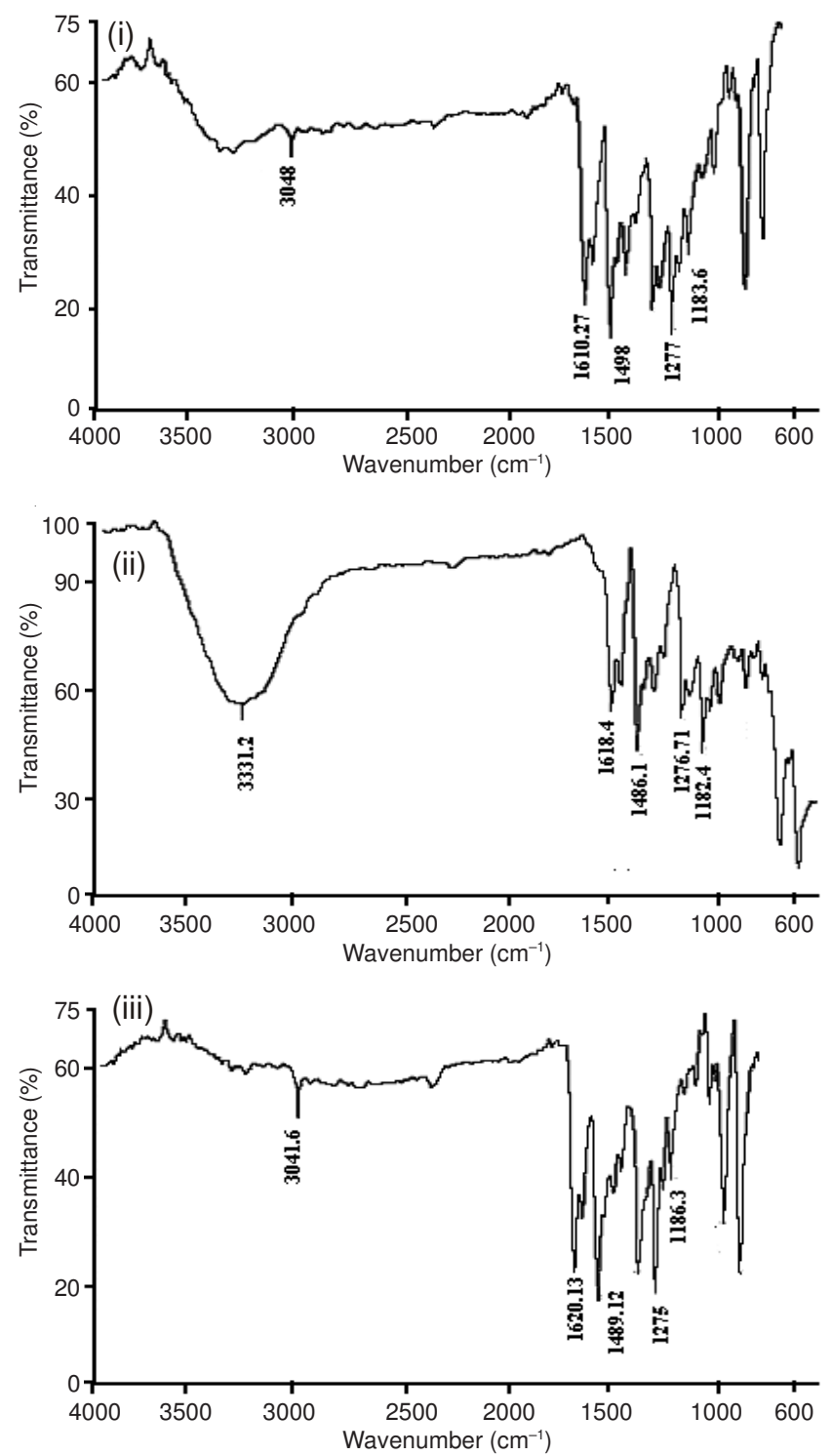


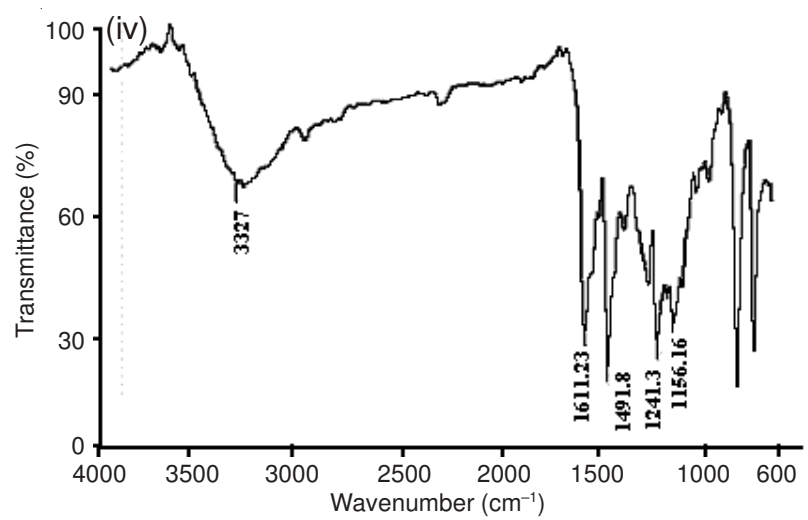

Fig. 1. IR spectra of new Schiff bases: (i) Bis-(o-hydroxylbenzaldehyde)1,2phenylenediimine; (ii) Bis-(o-hydroxylnaphthaldehyde)1,2phenylenediimine; (iii) Bis-(o-hydroxylbenzaldehyde)4aminophenylether; (iv) Bis-(o-hydroxylnaphthaldehyde)4aminophenylether

in $\mathrm{CDCl}_{3}$. The signals at proton of $\mathrm{OH}$ and $\mathrm{NH}$ groups were involved in the intra molecular hydrogen bonding. According to NMR spectra, the proton exists in the spectra of all four compounds indicated the presence of enol forms except the Schiff base $o$-hydroxynaphthaldehyde due to the mixture of keto-enol forms ${ }^{4}$.

Electronic absorption spectral properties: The UVvisible spectra of the compounds were studied in polar DMF and non-polar to $n$-hexane solvents ${ }^{13}$. The spectra are presented in Figs. 2-5 and summarized in Table-1. All compounds studied show one absorption band in the range of less that $400 \mathrm{~nm}$ but the new band (greater than $400 \mathrm{~nm}$ ) belongs to the keto form of the $o$-hydroxy Schiff bases in polar and non-polar solvents ${ }^{15,16}$. The band was observed in $o$-hydroxy naphthaldehyde 1,2phenylendiimine at greater than $400 \mathrm{~nm}$ in both polar DMF and non-polar $n$-hexane solutions. The enol-imine tautomer is dominant only in the polar solutions of DMF, in contrast to the keto-enamine tautomer. Solvent effects can be explained in term of the capability of solvents to form hydrogen bonding both as proton donors and as proton acceptors, thereby permitting proton transfers that result in formation of the keto form.

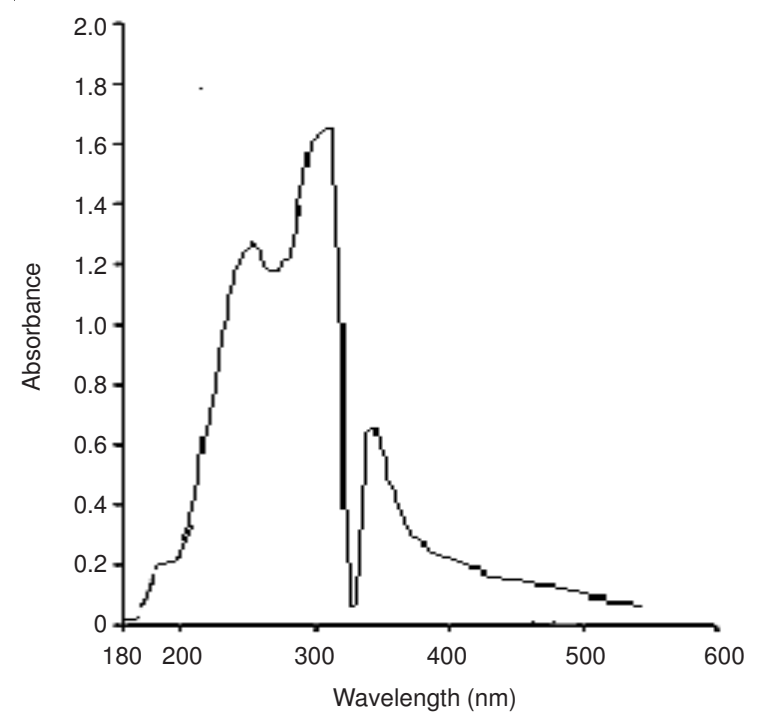

Fig. 2. UV-visible spectra of compound bis-(o-hydroxybenzaldehyde)1,2phenylenediimine in $n$-hexane

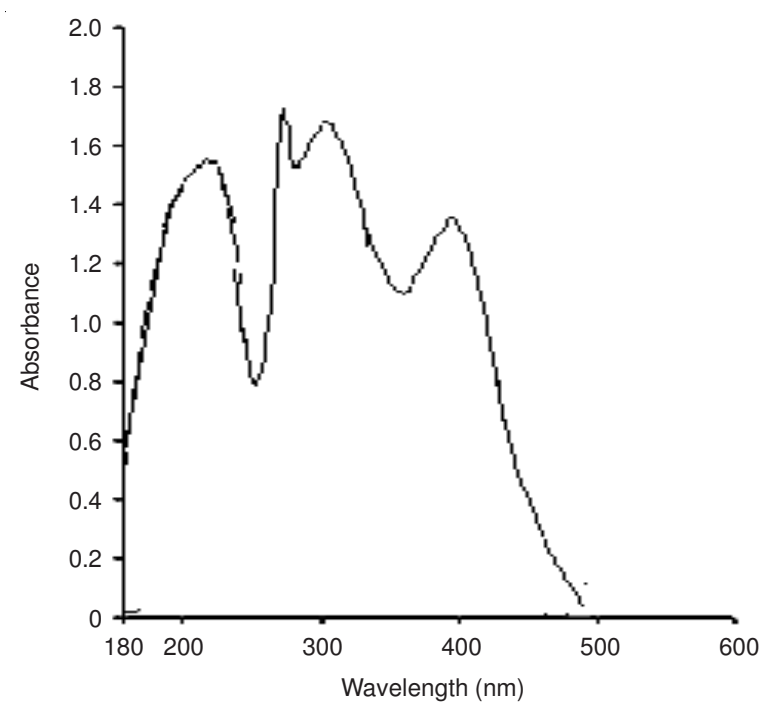

Fig. 3. UV-visible spectra of compound bis-(o-hydroxynaphthaldehyde) 1,2-phenylenediimine in $n$-hexane

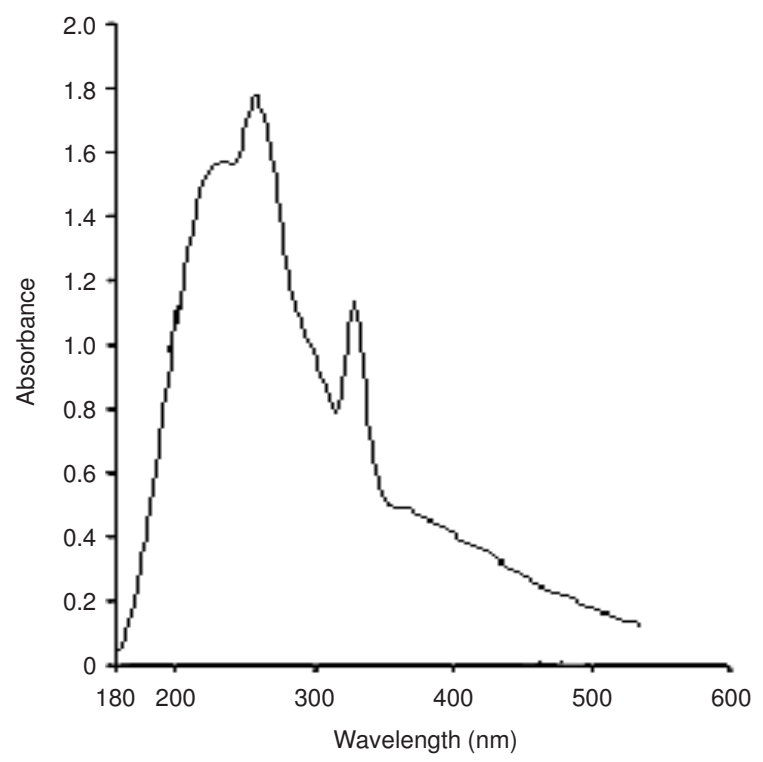

Fig. 4. UV-visible spectra of compound bis-(o-hydroxybenzaldehyde)4amino phenylether in $n$-hexane

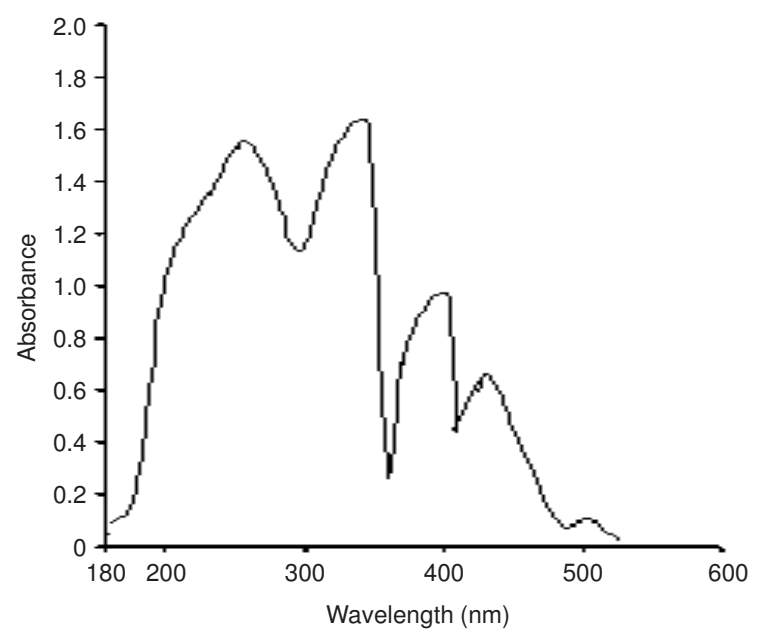

Fig. 5. UV-visible spectra of compound bis-(o-hydroxynaphthaldehyde)4amino phenylether in $n$-hexane 


\begin{tabular}{lccc}
\hline \multicolumn{4}{c}{ TABLE-1 } \\
ELECTRONIC SPECTRAL DATA OF \\
COMPOUNDS 2-HYDROXY SCHIFF BASE \\
\hline \multirow{2}{*}{ Compound } & $n$-Hexane & DMF & Molar \\
& $\lambda_{\max }(\mathrm{nm})$ & $\lambda_{\max }(\mathrm{nm})$ & coefficient \\
\hline Bis-(ortho- & 240 & 220 & 66560 \\
hydroxylbenzaldehyde) & 285 & 270 & 91520 \\
1,2-phenylenediimine & 310 & 300 & 33280 \\
\hline \multirow{2}{*}{ Bis-(ortho- } & 195 & 265 & 52140 \\
hydroxylnaphthaldehyde) & 265 & 315 & 56880 \\
1,2-phenylenediimine & 296 & 355 & 53720 \\
& 412 & 430 & 44240 \\
Bis-(ortho- & 226 & 220 & 78400 \\
hydroxylbenzaldehyde) & 265 & 260 & 88200 \\
4-aminophenylether & 305 & 310 & 56840 \\
& & 340 & 26650 \\
\hline \multirow{2}{*}{ Bis-(ortho- } & 234 & 230 & 106680 \\
hydroxylnaphthaldehyd) & 312 & 290 & 111760 \\
4-aminophenylether & 375 & 380 & 58420 \\
& 415 & 430 & 50800 \\
\hline
\end{tabular}

As a proton donor, the solvent interacts with the non-bonding electron pair of the azomethine nitrogen. Thus, it may be assumed that, in those Schiff base derivatives where a nonbonding electron pair is no longer available, a solvent effect will not be observed.

The spectroscopic data suggest that these compounds exist mainly in the enol-imine form in solid state for $o$-hydroxybenzaldehyde compounds and a mixture of enol and the keto form for $o$-hydroxynaphthaldehyde compound.

\section{Conclusion}

On the basis of spectroscopic data, the $o$-hydroxy Schiff bases or derivatives have a course of an additional role in the process, which played by intramolecular hydrogen bonding. In contrast with the formation of keto form, the possibility of enol form is raised in all compounds because when a molecule pass from keto to enol then a $\mathrm{H}$ - bonding exist which make it more stable. And the compound $o$-hydroxynaphthaldehyde have a mixture of keto-enol forms in both polar and non-polar solvents.

\section{REFERENCES}

1. A.N. Papadopoulos, C.P. Raptopoulou, A. Terzis, A.G. Hatzidimitriou, A. Gourdon and D.P. Kessisoglou, J. Chem. Soc. Dalton Trans, 2591 (1995).

2. F.S. Kamounah, S.R. Salman and A.A.K. Mahmoud, Spectrosc. Lett., 31, 1557 (1998).

3. M. Sakamato, Y. Nishida, K. Ohhara, Y. Sadaoka, A. Matsumato and H. Okawa, Polyhedron, 14, 2505 (1995).

4. $\quad$ S.R. Salman and N.A. Saleh, Spectrosc. Lett., 30, 1289 (1997).

5. Z. Popovic, V. Roje, G. Pavlovic, D. Matkovic-Calogovic and G. Giester, J. Mol. Struct., 597, 39 (2001).

6. S.R. Salman, S.H. Shawkat and G.M. Al-Obaidi, Spectrsc. Lett., 31, 221 (1998).

7. S. Shasad, S.D. Gleb, D.T. Michael and L. Hans-Heinrich, J. Am. Chem. Soc., 128, 3379 (2006).

8. H. Nazir, M. Yildiz, H. Yilmaz, M.N. Tahir and D. Ulku, J. Mol. Struct., 524, 241 (2000).

9. T. Hokelek, N. Akduran, M. Yildiz and Z. Kilic, Anal. Sci., 16, 553 (2000).

10. M. Rospenk, I. Król-Starzomska and A. Filarowski, Chem. Phys., 287, 113 (2003).

11. H. Unver, M.Yildiz, D.M. Zengin, S. Zbey and E. Kendi, J. Chem. Crystallogr., 31, 211 (2002).

12. S.H. Alarcón, D. Pagani, J. Bacigalupo and A.C. Olivieri, J. Mol. Struct., 475, 233 (1999).

13. H. Joshi, F.S. Kamounah, G. van der Zwan, C. Gooijer and L. Antonov, J. Chem. Soc., Perkin Trans. II, 12, 2303 (2001).

14. R. Harzfeld and P. Nagy, Spectrosc. Lett., 32, 57 (1999).

15. R. Herzfeld and P. Nagy, Curr. Org. Chem., 5, 373 (2001).

16. H. Joshi, F.S. Kamounah, C. Gooijer, G. van der Zwan and L. Antonov, J. Photochem. Photobiol. A, 152, 183 (2002).

17. M. Gavranic, B. Kaitner and E. Mestrovic, J. Chem. Crystallogr., 26, 23 (1996).

18. H. Ünver, D.M. Zengin and K. Güven, J. Chem. Crystallogr., 30, 359 (2000).

19. T. Dziembowska, Z. Rozwadowski, A. Filarowski and P.E. Hansen, Magnatic Resonance Chem., 39, 67 (2001).

20. L. Antonov, M.F. Fabian, D. Nedeltcheva and F.S. Kamounah, J. Chem. Soc., Perkin Trans. II, 1173 (2000).

21. G.J.M. Fernández, F. del Rio-Portilla, B. Quiroz-García, R.A. Toscano and R. Salcedo, J. Mol. Struct., 561, 197 (2001).

22. S.D. Chatziefthimiou, Y.G. Lazarou, E. Hagjoudis, T. Dziembowska and I.M. Mavridis, J. Phys. Chem. B, 110, 23701 (2006).

23. J. Zawadiak and M. Mrzyczek, Spectrochim. Acta A, 75, 925 (2010).

24. D. Yanagissawa and N. Shirai, Biomaterial, 31, 4179 (2010).

25. S. Samal, R.R. Das, D. Sahoo, S.Acharya, R.L. Panda and R.C. Rout, J. Appl. Polym. Sci., 62, 1437 (1996). 